\title{
Dynamics of non-linear cortico-cortical interactions during motion integration in early visual cortex: a spiking neural network model of an optical imaging study in the awake monkey
} Jens Kremkow*1,2, Laurent Perrinet ${ }^{1}$, Alexandre Reynaud ${ }^{1}$, Ad Aertsen ${ }^{2,3}$, Guillaume S Masson ${ }^{1}$ and Frederic Chavane ${ }^{1}$

\author{
Address: ${ }^{1}$ INCM, CNRS-Aix-Marseille University, Marseille, France, ${ }^{2}$ Neurobiology and Biophysics, University of Freiburg, Freiburg, Germany and \\ ${ }^{3}$ Bernstein Center for Computational Neuroscience, Freiburg, Germany \\ Email: Jens Kremkow* - kremkow@biologie.uni-freiburg.de \\ * Corresponding author
}

from Eighteenth Annual Computational Neuroscience Meeting: CNS*2009

Berlin, Germany. 18-23 July 2009

Published: 13 July 2009

BMC Neuroscience 2009, I0(Suppl I):PI76 doi:I0.I|86/I47|-2202-I0-SI-PI76

This abstract is available from: http://www.biomedcentral.com/I47I-2202/I0/SI/PI76

(c) 2009 Kremkow et al; licensee BioMed Central Ltd.

\section{Introduction}

Lateral interactions are crucial mechanisms in contextual modulation of visual processing, including visual motion. We have recently shown, using voltage-sensitive dye imaging (VSDI), that a local static stimulus (Gaussian blob) first activates a restricted cortical area, followed by slow horizontal propagation of activity along the cortex [1]. In a sequence of two local static stimuli, two-stroke apparent motion, the two waves of horizontal activation interact non-linearly in V1, giving rise to a gradual and smooth wave of normalized activity. This signature of non-linear integration was a wave of suppression traveling from the representation of the second stimulus towards the first stimulus. To investigate the cellular and network mechanisms underlying these non-linear lateral interactions, we constructed a two-dimensional cortical network model using spiking neurons with conductance-based synapses. The model represents cortical layer 2/3, the main source of the VSDI signals. The connectivity of the inhibitory neurons was restricted to the local neighborhood, whereas the excitatory neurons could, in addition, also make long-range horizontal connections. The physiology of these horizontal connections was adjusted to induce balanced excitation/inhibition at high activity levels [2]. To compare the model dynamics to the in vivo VSDI signals, we extracted a model VSDI signal by recording the membrane potentials of many neurons arranged on a fine rectangular grid. The model was written in PyNN [3] using NEST [4] as a simulator. Our simulations reproduced the experimental observations of slow horizontal propagation when stimulating the network by a single static stimulus. In the two-stroke apparent motion paradigm, the model reproduced the non-linear integration by a wave of suppression. The origin and dynamics of this suppression were caused by the activity-dependent amount of local inhibition balancing the effect of the excitatory lateral connections. Physiological data shows that similar wave of suppression could be observed with a wide range of spatio-temporal two stroke input, but also with "real motion" stimuli. We therefore generalized our study to conditions during which the stimulus speed varies according to the suppressive spread velocity. Thus, our model suggests that the wave of non-linear integration observed in vivo could be caused by local inhibition balancing the integration of horizontal inputs. Moreover, it highlights the importance of contextual modulation for visual processing.

\section{Acknowledgements}

This work was supported by the CNRS, the 6th RFP of the EU (grant no. I5879-FACETS) and by the German Federal Ministry of Education and Research (BMBF grant 0IGQ0420 to BCCN, Freiburg). 


\section{References}

I. Chavane F, Reynaud A, Masson GS: The role of cortico-cortical interactions during motion integration: a voltage-sensitive dye imaging study in $\mathrm{VI}$ and $\mathrm{V} 2$ of the awake monkey. [Abs.]. Journal of Vision 8:226.

2. Hirsch JA, Gilbert CD: Synaptic physiology of horizontal connections in the cat's visual cortex. I Neurosci I991, I I:I800-I809.

3. Davison A, Brüderle D, Eppler J, Kremkow J, Muller E, Pecevski D, Perrinet L, Yger P: PyNN: a common interface for neuronal network simulators. Front Neuroinform 2008, 2: I I.

4. Gewaltig MO, Diesmann M: NEST (NEural Simulation Tool). Scholarpedia 2007, 2:1430.

Publish with Bio Med Central and every scientist can read your work free of charge

"BioMed Central will be the most significant development for disseminating the results of biomedical research in our lifetime. "

Sir Paul Nurse, Cancer Research UK

Your research papers will be:

- available free of charge to the entire biomedical community

- peer reviewed and published immediately upon acceptance

- cited in PubMed and archived on PubMed Central

- yours - you keep the copyright 